\title{
Inactivation of Surface-Borne Microorganisms and Increased Germination of Seed Specimen by Cold Atmospheric Plasma
}

\author{
Anindita Mitra • Yang-Fang Li • Tobias G. Klämpfl • \\ Tetsuji Shimizu • Jin Jeon • Gregor E. Morfill • \\ Julia L. Zimmermann
}

Received: 19 October 2012 / Accepted: 9 May 2013 / Published online: 26 May 2013

(C) The Author(s) 2013. This article is published with open access at Springerlink.com

\begin{abstract}
Sustaining the quality of seeds is a major task in attempting to supply nutrition to the growing world population. In this study, the seeds of Cicer arietinum were exposed to cold atmospheric plasma (CAP). A significant reduction of the natural microbiota attached to the seed surface was observed for increasing CAP treatment times -2 and 5 min were sufficient to achieve a 1 and 2 $\log$ reductions, respectively. Furthermore a 1 min CAP treatment showed a strongly improved seed germination $(89.2 \%)$, speed of germination (7.1 \pm 0.1 seeds/day), and increased seed vigor, beside a decrease in the mean germination time (2.7 days) compared with controls. The roughness profile of the seed cotyledon was altered significantly, only in case of longer treatment times from $5 \mathrm{~min}$. These results suggest that CAP technology has the potentiality to reduce health risks associated with contaminated seeds, while improving food quality.
\end{abstract}

Keywords Cold atmospheric plasma $\cdot$ Seed borne microorganisms $\cdot$ Seed treatment $\cdot$ Seed germination

$\begin{array}{ll}\text { Abbreviations } \\ \text { CAP } & \text { Cold atmospheric plasma } \\ \text { CFU } & \text { Colony forming units } \\ \text { SMD } & \text { Surface micro-discharge } \\ \text { LPCP } & \text { Low pressure cold plasma } \\ \text { MGT } & \text { Mean germination time }\end{array}$

A. Mitra • Y.-F. Li • T. G. Klämpfl • T. Shimizu • J. Jeon •

G. E. Morfill $\cdot$ J. L. Zimmermann

Max Planck Institute for Extraterrestrial Physics, 85748 Garching, Germany

A. Mitra $(\bowtie)$

Max-Planck Institute for Extraterrestrial Physics,

Giessenbachstrasse, 85748 Garching, Germany

e-mail: mitra@mpe.mpg.de

\section{Introduction}

Contaminated seeds are one of the main concerns for most reported sprout-associated outbreaks (Anonymous 1999). If moisture content exceeds the permissible level for safe storage of the durable dry products, microflora may develop on seed surface that ultimately affect the sprout quality at the time of germination process. However, seeds can be contaminated during postharvest operations of transport, conditioning, grading, storage, and packaging. The National Advisory Committee on Microbiological Criteria for Foods (NACMCF, USA) has reviewed the current industrial practices related to growing of seeds and the production of sprouts and developed several recommendations on food safety, seed production, seed handling, seed treatment, and sprout production processes (Anonymous 1999). They investigated that the lack of consistent seed disinfection treatments prior to sprouting is one of the main reasons for recent sprout associated outbreaks. Since seeds are the primary source of sprout associated microbial contaminations, much of the research on relevant prevention and intervention technologies is at the moment focused on reducing seed-associated microbiota from seeds prior to sprouting.

Fungal species of Aspergillus, Trichoderma, Penicillium, Botrytis, Sclerotinia, and Rhizopus are pertinent to dry seed products during storage, where saprophytic microflora can develop and cause damage at suitable temperatures and moisture content (Navarro \& Donahaye, 2005). Toxins produced by some fungi-like Aspergillus flavus may render the food inedible and may sometimes cause internal hemorrhage and even carcinogenesis (Maity et al. 2004). Salmonella spp., Listeria monocytogenes, Staphylococcus aureus, Bacillus cereus, and Aeromonas hydrophila were isolated from different sprouted seeds of alfalfa, mung bean, cress, soybean, and mustard (Beuchat 1996). Escherichia coli O157, various serotypes of Salmonella, and Bacillus 
cereus were documented as the causative agents of outbreaks of foodborne illness associated with sprouts (Fett 2006).

The recent outbreak of enterohemorrhagic E. coli contaminated sprouts in Germany (Buchholz et al. 2011) and the following huge uncertainty for consumers drew a lot of attention to this topic and to the demand for improved hygiene, i.e., inactivation of microorganisms on sprouts/raw foods/seeds without affecting their properties is increased. This has been recognized by different higher authorities just as the Food and Agriculture Organization (FAO) of the United Nations, the Food and Drug Administration (FDA of the US), and the World Health Organization (WHO), which investigate food safety and associated problems in detail. Hence, many seed decontamination procedures were tested on artificially contaminated seeds (Fett 2006) with Salmonella spp. and enterohemorrhagic E. coli O157. In contrast to this study, very few studies have been reported on the disinfection of the naturally contaminated seed surface. It is a distinct approach in comparison to these tests with artificially contaminated seed surfaces, since naturally occurring microorganisms can be attached to the seed surface even in the narrow gaps for a long time as microcolonies or biofilms and are therefore harder to inactivate (Izquier \& Gómez-López 2011).

In addition to seed disinfection, loss of seed survivability due to microbial contamination, low percentage of germination, and longer germination time are three other major issues in germination process. Former researchers treated natural microflora from seeds with sodium or calcium hypochlorite, ozonized water, or hydrogen peroxide but were not successful to eliminate it completely (Anonymous 1999). Furthermore, these treatments affect seed germination and produce waste, which is a subject of environmental concern. That is why the NACMCF recommends exploring other physical nonthermal technologies in sprout production.

Recent reports showed the potentiality of physical cold atmospheric plasmas (CAPs) in the field of life sciences (Laroussi 2005; Morfill et al. 2009). Food/seed disinfection studies (Basaran et al. 2008; Selcuk et al. 2008) and seed germination/seed viability studies (Será et al. 2008; Zhou et al. 2011; Dubinov et al. 2000) were carried out using different plasma sources that create different concentrations of plasma reactive species, charged particles, and photons. Their approach for studying seed decontamination contained artificially inoculated pathogens on different food surfaces, which were exposed to CAP.

In this study, seeds of Cicer arietinum, commonly known as chickpeas or garbanzo beans, were used. This leguminous food is a rich source of carbohydrate, protein, vitamins, and minerals (Costa et al. 2006) and is especially grown across America, Africa, Middle East, Asia, the Mediterranean basin, and Australia (FAOSTAT 2004).
In this context, this study was conducted using CAP combining the analysis of its inactivation properties on naturally attached microorganisms on seed surface and of its effects on seed germination.

\section{Methods}

Plasma Device

\section{Experimental Setup}

The plasma device, FlatPlaSter 2.0 (Fig. 1), used in this study incorporates an electrode based on the surface micro-discharge (SMD) technology using ambient air, which is explained in detail by Morfill et al. (2009).

The plasma electrode itself has a size of $13 \times 9 \mathrm{~cm}^{2}$ and consists of a Teflon plate, which is separating a brass planar plate from a stainless steel mesh grid. The electric power required to generate plasma was supplied by a Danfoss (EBI4 series) generator that created a repetitive voltage cycle: The first stage produced high voltage $\left(17 \mathrm{kV}_{\mathrm{pp}}\right.$ for $2 \mathrm{~ms})$, the second low voltage $\left(5 \mathrm{kV}_{\mathrm{pp}}\right.$ for $\left.8 \mathrm{~ms}\right)$, and the third no voltage for $10 \mathrm{~ms}$. Many plasma micro-discharges were generated in the ambient air at the mesh grid edges of the electrode for the first of the three voltage stages $\left(17 \mathrm{kV}_{\mathrm{pp}}\right.$ for $2 \mathrm{~ms})$. The power density of the device was $10 \mathrm{~mW} / \mathrm{cm}^{2}$.

The described plasma electrode is incorporated in a polyoxymethylene-copolymer (POM-C) box at the upper part of the device (Fig. 1). The plasma was ignited above the samples. During the plasma treatment, the door of the POM-C box was closed to confine the species produced by SMD air plasma.

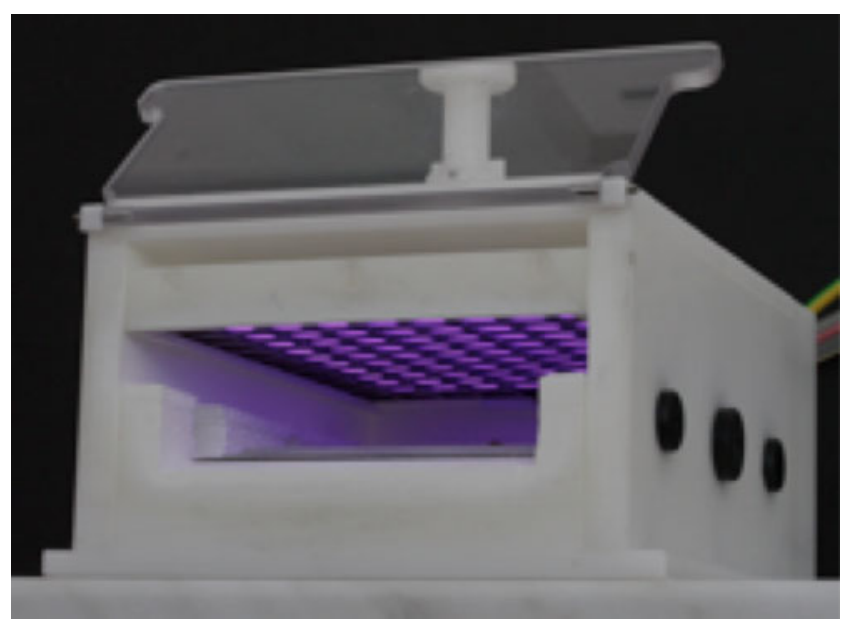

Fig. 1 The plasma device (FlatPlaSter 2.0) containing one SMD electrode, which is located inside in the upper part of the device. The samples were treated beneath the electrode 


\section{Characterization of the Plasma Device}

The main reactive plasma constituents produced by the FlatPlaSter 2.0 in ambient air were measured. In summary, the process temperature increased to maximum $5{ }^{\circ} \mathrm{C}$ above ambient temperature during treatment period. The main UV components of the emission spectrum (measured with an Avantes spectrometer, AvaSpec-2048) were in the wavelength range between 280 and $400 \mathrm{~nm}$ (data not shown), which can be mainly attributed to the excitation of molecular nitrogen in air. That means, the UVC light was almost absent, whereas UVA and UVB were active plasma components. The UV power density was measured to be below $0.2 \mu \mathrm{W} / \mathrm{cm}^{2}$. Concerning the toxic gas production of the device, the mean concentration values of $\sim 1,000 \mathrm{ppm}$ for $\mathrm{O}_{3}$ for a treatment time of $2 \mathrm{~min}$ (measured with UV absorption spectrometry at $254 \mathrm{~nm}$ ), $<0.1 \mathrm{ppm}$ for $\mathrm{NO}$, and $3 \mathrm{ppm}$ for $\mathrm{NO}_{2}$ for a treatment time of $5 \mathrm{~min}$, were measured (using chemiluminescence $\mathrm{NO}_{\mathrm{X}}$ analyzer). In this experiment, the electrical current through the sample was negligibly small, as the device produces micro-discharges without being in touch with the samples.

\section{Samples and CAP Treatment}

The seed grains $(C$. arietinum) were collected from the local market. They were immersed in tap water for $5 \mathrm{~min}$; the excess water was drained off, and the seeds were air-dried for $5 \mathrm{~h}$. The seed moisture content was determined by oven drying at $95{ }^{\circ} \mathrm{C}$. The average moisture content of the tested seeds was in the range of $12-15 \%$ wet basis. Six sets of 140 seeds divided into seven parts were stored in sterile polythene bags for further processing.

The seeds were exposed to CAP in the FlatPlaSter 2.0 for different time intervals $(0.5$ to $5 \mathrm{~min})$. Since microbial inactivation has been proved to differ depending upon the distance to the plasma electrode ( $\mathrm{Li}$ et al. 2012), the seeds in the sample holder were placed beneath the electrode at a distance of $13.5 \mathrm{~mm}$. Every seed had a minimum contact area of $0.196 \mathrm{~cm}^{2}$ with the sample holder. All experiments were repeated six times.

\section{Analytic Methods}

\section{Surface Area of the Seeds}

The effects of CAP species on seeds depend on their surface area, over which plasma diffusion takes place. Furthermore, the microorganisms on the seed surface are also affected by the CAP treatment. Considering the seed surface as the CAP affected region and assuming that the seed shape is ellipsoidal, the surface area $S$ of a single seed (Chenoll et al. 2009) was calculated using the modified equation of a sphere:

$\mathrm{S}\left(\mathrm{cm}^{2}\right)=2 \pi \mathrm{a}^{2}+\frac{2 \pi \mathrm{ac}}{\mathrm{E}_{\mathrm{c}}} \sin ^{-1} \mathrm{E}_{\mathrm{c}}$

where $E_{c}$, the eccentricity coefficient, expresses the degree of similarity between an ellipsoid and a sphere and was obtained from,

$E_{c}=\sqrt{1-\frac{a^{2}}{c^{2}}}$

The three axis $(a, b, c)$ system of the seeds (Fig. 2) was measured by using a slide caliper.

\section{Microbial Counts}

For microbial analysis, the CAP-treated and untreated seed samples were randomly selected and mixed with $90 \mathrm{~mL}$ of $0.1 \%$ peptone solution in a sterile test tube by vortexing. After proper dilution, $50 \mu \mathrm{L}$ samples were spread onto Müller-Hinton agar media and incubated at $35{ }^{\circ} \mathrm{C}$ for 24 $48 \mathrm{~h}$. The surviving colony-forming units $(\mathrm{CFU} / \mathrm{mL})$ were expressed corresponding to the surface area $\left(\mathrm{CFU} / \mathrm{mL} / \mathrm{cm}^{2}\right)$ of the seeds. Six replicated samples from each treated and untreated groups were used for the study and from each replicate, one seed sample was used for the microbial count.

\section{Moisture Content and Membrane Permeability of the Seeds}

To determine the percentage of moisture loss due to the CAP exposure, the seeds were weighed before and after the CAP treatments by using an electronic balance. From these

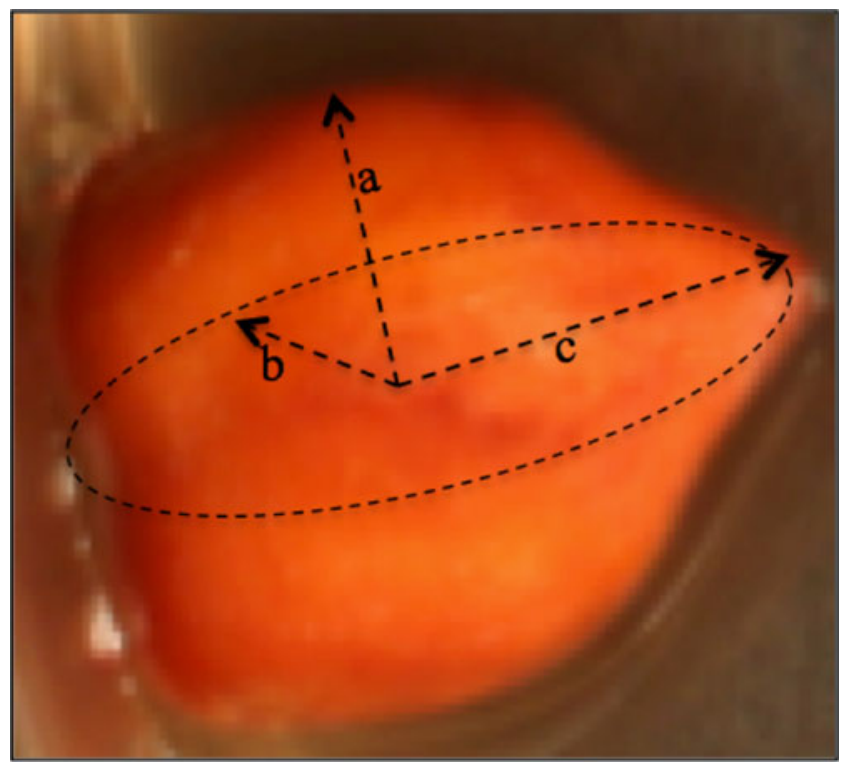

Fig. 2 The three axis $(\mathbf{a}-\mathbf{c})$ system of Cicer arietinum, which is considered as an ellipsoid 
measurements, the relative weight loss of the seeds was calculated.

For the seed membrane permeability analysis, about $1 \mathrm{~g}$ of CAP-treated and untreated seeds were dipped into $50 \mathrm{~mL}$ of deionized water to allow ions to leach through the seed membrane into the water. The conductivity of water was measured using the Sartorius professional meter PP-20 after 24 and $48 \mathrm{~h}$ intervals to quantify the ions leached through the seed membrane (Maity et al. 2004). Both experiments were repeated six times.

\section{Germination Test}

The seed germination tests were carried out with twenty CAP-treated or untreated seeds with six replicates. The exposed and nonexposed seeds were arranged on a sterile wetted blotter in a Petri dish (90 $\mathrm{mm}$ in diameter) and incubated at $28{ }^{\circ} \mathrm{C}$ with $90 \%$ relative humidity. The progress of germination was measured every $24 \mathrm{~h}$ by registering the emergence of the radicle, until no more seeds germinated. To quantify the germinated seeds properly, the method described by Será et al. (2008) was used. The mean germination time (MGT) was calculated following the procedure of Sadeghi et al. (2011) (Eq. 3). Here, $n$ is the number of seeds that germinated after $t$ days and were counted from the beginning of germination.

MGT $=\frac{\sum t n}{\sum n}$

The speed of germination $\left(V_{g}\right)$ was determined following Maguire (1962), where $n_{t}$ is the number of newly germinated seeds at time $t$, counted from the first day (Eq. 4).

$V_{\mathrm{g}}=\sum\left(\frac{\mathrm{n}_{\mathrm{t}}}{\mathrm{t}}\right)$

For each group, the shoot and root length of ten randomly selected germinated seeds were measured in centimeter after 7 days. Subsequently, they were oven dried at $90{ }^{\circ} \mathrm{C}$ to measure the dry weight (Shine et al. 2011). The seedling vigor index, a parameter describing the seedling health, was obtained according to Abdul-Baki and Anderson (1973).

\section{Microscopy and Image Analysis}

Digital photos of the inner surfaces of seed cotyledon were taken before and after each CAP treatment using the Keyence digital microscope VHX-600 with $\times 5,000$ optical lens (Murthy 2011). For depth profiling, the image stacks were collected under identical conditions (i.e., similar area and vertical resolution) at $5 \mu \mathrm{m} \mathrm{Z}$ intervals. The mean value of three samples of each group was utilized for stack preparation. The depth surface profile was extracted using the
Keyence software. Image J (Schneider et al. 2012), an opensource software, was used for further processing of the image stacks with the interactive 3D surface plot (2011) plug-in and SurfCharJ plug-in (Chinga et al. 2007), in order to evaluate the depth profile and the surface roughness, respectively. For better characterization of the surface roughness, the parameters like the "root mean square deviation $\left(\mathrm{R}_{\mathrm{q}}\right)$ " and the "kurtosis of the assessed profile $\left(\mathrm{R}_{\mathrm{ku}}\right)$ " were tested, along with the most commonly used parameter, the "average roughness $\left(R_{a}\right)$ ". The details of these parameters are described in detail by Chandrasekaran et al. (2005). In short, the " $\mathrm{R}_{\mathrm{a}}$ " corresponds to the vertical deviation of the arithmetic mean. The " $\mathrm{R}_{\mathrm{q}}$ " is the square root of the vertical deviation of the arithmetic mean, and the " $R_{\mathrm{ku}}$ " describes the peakedness of the height distribution. This experiment was intended for the investigation of the surface roughness on a microscopic scale and not on a molecular level, in order to understand the overall roughness scenario of plasmatreated and untreated seeds.

\section{Modeling and Statistical Analysis}

As inactivation kinetics do not always follow the first order log-linear relationships, the software GlnaFIT, developed by Geeraerd et al. (2005) was used. With this tool, the two different microbial survival models, the "log-linear model" (Eq. 5, Bigelow and Esty 1920) and the "Weibull model" (Eq. 6, Mafart et al. 2002), developed as a function of time, were tested.

$\log _{10}(\mathrm{~N})=\log _{10}\left(\mathrm{~N}_{0}\right)-\mathrm{k}_{\max } \times \frac{\mathrm{t}}{\operatorname{In} 10}$

$\log _{10}(\mathrm{~N})=\log _{10}\left(\mathrm{~N}_{0}\right)-\left(\frac{\mathrm{t}}{\delta}\right) \mathrm{p}$

Where $N\left(\mathrm{CFU} / \mathrm{mL} / \mathrm{cm}^{2}\right)$ is the number of survivors, $N_{0}$ $\left(\mathrm{CFU} / \mathrm{mL} / \mathrm{cm}^{2}\right)$ is the initial number of microorganisms, $k_{\max }$ is the inactivation rate, and $\delta$ is the time for first decimal reduction of microorganisms due to the treatment.

All the data were represented as means \pm standard error of the mean. The mean data were statistically analyzed using Student's $t$ test. The level of significance was considered at $p \leq 0.05$.

\section{Results and Discussion}

Effect of CAP on the Microorganisms on the Seed Surface

The microorganisms on $C$. arietinum seed surfaces (initial natural microbial load on the seed surface is $4.5 \pm 0.02$ (log $\mathrm{CFU} / \mathrm{mL} / \mathrm{cm}^{2}$ ) were exposed to CAP for $30 \mathrm{~s}, 1,2,3$, 4, and 
$5 \mathrm{~min}$, respectively. The inactivation results are depicted in Fig. 3. The survival curve showed a significant reduction of the microbial count $\left(\log \mathrm{CFU} / \mathrm{mL} / \mathrm{cm}^{2}\right)$ for increasing CAP treatment times. In the case of 2 and 5 min treatments, a reduction of nearly 1 and $2 \log$ was achieved, respectively. Based on this data, two models were generated with the GlnaFIT tool. These models were validated with parameters like root mean sum of squared errors and $R^{2}$ values (Table 1). Furthermore, the models focused on the number of log cycle reduction rather than on the classical D-value. The Weibull model fitted the obtained data better and was therefore plotted in Fig. 3. The curve shows an upward concavity and no shoulder or tail. However, the inactivation results were not only dependent on the CAP treatment time but also strongly related to the size and shape of the seeds and the minimum contact area of the samples with the holder (data not shown).

Seed wrinkle and crevices could be another factor that create barrier to reach the used disinfecting treatment procedure to the microflora (Caetano-Anolles et al. 1990; Charkowski et al. 2001). In this respect, CAP treatment must be optimized for curved biological surfaces like seed surface (Schnabel et al. 2012). Shaking of samples during CAP treatment could ensure a uniform exposure of the whole seed surface to plasma. This is reasonable, since the various reactive species in gas state from the SMD air plasma device has to reach microorganisms on the samples for the inactivation process. The CAP derived reactive oxygen and nitrogen species ( $\mathrm{NO}, \mathrm{OH}$, superoxide) or strong oxidizing agents $\left(\mathrm{H}_{2} \mathrm{O}_{2}, \mathrm{O}_{3}\right)$ might penetrate into microorganisms and alter the cell processes, and thus inactivate them (Klämpfl et al. 2012). However, it is well-established that $\mathrm{H}_{2} \mathrm{O}_{2}$ and $\mathrm{O}_{2}^{-}$plays an important role in pathogen defense in seeds (Kranner et al. 2010). Nevertheless, in

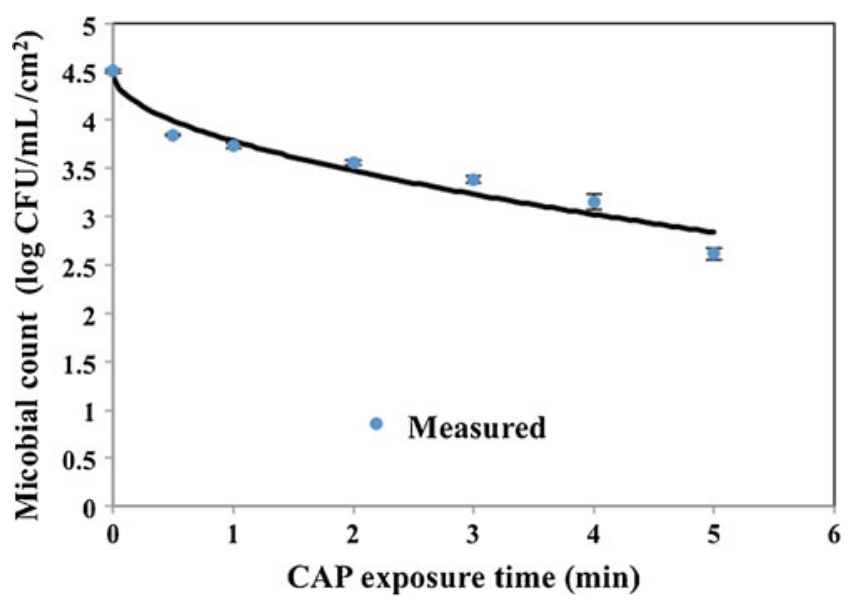

Fig. 3 Survival curve of the surface microorganisms on Cicer arietinum due to CAP exposure represented with the Weibull model. The data points represent mean value \pm SEM $\log \mathrm{CFU} / \mathrm{mL} / \mathrm{cm}^{2}$. Maximum SEM was 0.06
Table 1 Kinetics parameters of the two fitting models for inactivation of surface microorganisms of Cicer arietinum treated with CAP

\begin{tabular}{lll}
\hline Parameter & Log-linear model & Weibull model \\
\hline $\mathrm{RMSE}$ & 0.20 & 0.17 \\
$\mathrm{R}^{2}$ & 0.90 & 0.94 \\
$\log _{10}\left(\mathrm{~N}_{0}\right)\left(\mathrm{CFU} / \mathrm{mL} / \mathrm{cm}^{2}\right)$ & $4.2 \pm 0.1$ & $4.5 \pm 0.2$ \\
$\mathrm{~K}_{\max }(1 / \mathrm{min})$ & $0.7 \pm 0.1$ & \\
$\delta(\min )$ & & $2.1 \pm 0.8$ \\
$\mathrm{p}$ & & $0.6 \pm 0.2$ \\
\hline
\end{tabular}

RMSE root mean sum of squared error, $\log _{10}\left(\mathrm{~N}_{0}\right)$ predicted logarithm of initial count, $K_{\max }$ specific inactivation rate, $\delta$ time for the first decimal reduction, $p$ dimensionless parameter describing concavity or convexity of the curve

order to achieve shelf life extension for food/seed, considerable amount of microbial reductions are necessary. In the guideline for the microbiological quality of some ready-toeat foods, Gilbert et al. (2000) mentioned that the aerobic microbial load should be maintained within the acceptable range in different food categories.

Previously, CAPs were used to decontaminate artificially inoculated seed surfaces (Schnabel et al. 2012; Selcuk et al. 2008). Using dielectric barrier discharges, Schnabel et al. (2012) decontaminated seeds of Brassica napus from Bacillus atrophaeus spores achieved $0.7 \log$ reduction after a 15 -min treatment. We have already shown that bacterial endospores on stainless steel and on other surfaces could be inactivated (Klämpfl et al. 2012) with our device at distinct plasma power setting. Thus, the spore inactivation on seeds might be also feasible with such setup.

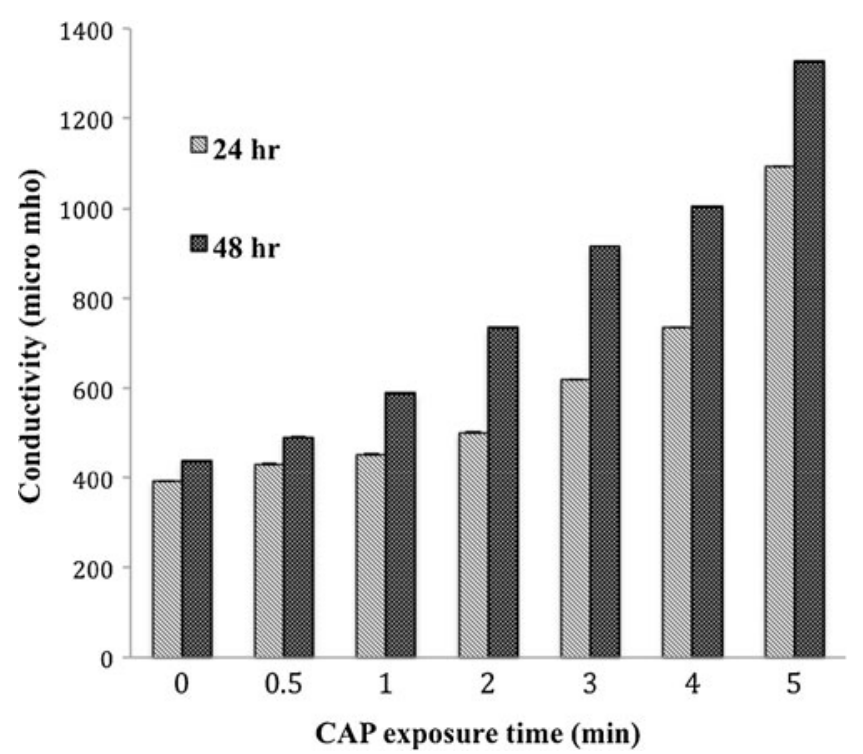

Fig. 4 Leached ions from Cicer arietinum due to different CAP treatment times. The bars represent mean value \pm SEM micro mho. The error bars are too small to be visible $(n=6 ; p<0.05)$. Maximum SEM was 1.12 


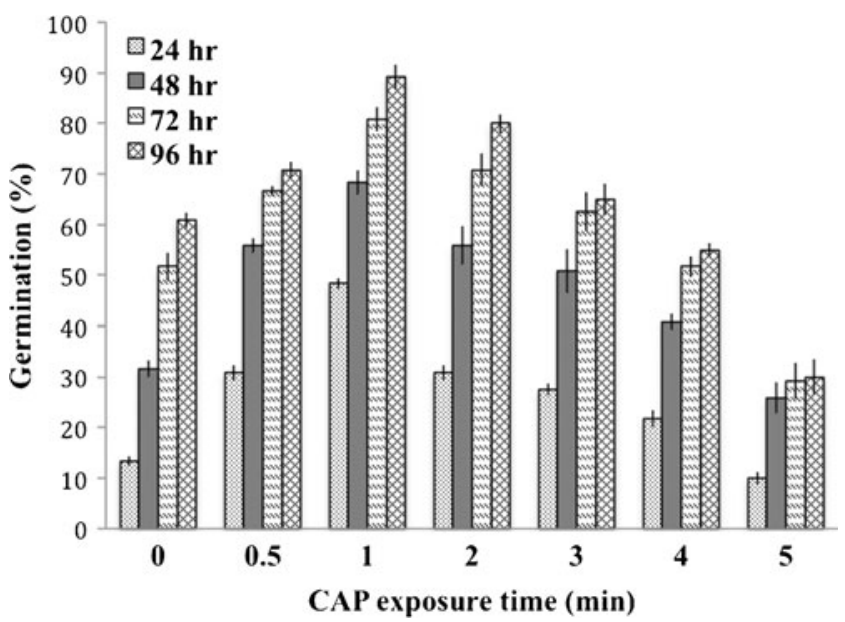

Fig. 5 Influence of CAP (0-5 min exposure) on the seed germination behavior of Cicer arietinum. The bars show mean value \pm SEM germination $(\%)(n=6 ; p<0.05)$

Selcuk et al. (2008) contaminated seeds of wheat, barley, oats, lentil, rye, corn, and chickpea with Aspergillus sp. and Penicillum sp. and treated them with LPCP, using air gasses and sulfur hexafluoride for the time duration of 5-20 $\mathrm{min}$. The study concluded that the decontamination of seeds does not only depend on the used plasma gas and treatment duration but also on the surface and type of the contaminated seeds.

Nevertheless, this study shows, for the first time, the decontamination effect of CAP on natural microbiota attached to the seed surface.

CAP Effect on Seed Membrane Permeability and Moisture Content

The seed membrane permeability is directly linked to the nutrient supply of the embryo. Significant alteration of the membrane of the seed coat affects the seed growth. Furthermore, a loss of cell membrane integrity causes an increase in leachate conductivity. In this study, the conductivity was measured to assess the extent of damage imposed on the seed membranes. The result showed that, due to the CAP treatment times ranging from $30 \mathrm{~s}$ to $5 \mathrm{~min}$, the seed membrane permeability changed (Fig. 4). For a $1 \mathrm{~min}$ CAP treatment, the conductivity increased only by 15.3 and $34.3 \%$ compared to the control after 24 and $48 \mathrm{~h}$, respectively. Longer treatment times of $5 \mathrm{~min}$ lead to an increase by 177.9 and $237.7 \%$ compared to the control after 24 and $48 \mathrm{~h}$, respectively.

After 5 min, CAP treatment moisture content was reduced by $1.2 \%$ compared to the control, where for $1 \mathrm{~min}$ CAP treatment, it was $0.9 \%$ reduction. However, no studies were carried out so far on the effect of conductivity and loss of moisture content in seeds due to the CAP treatment.

\section{Seed Germination}

Following the inactivation studies and the analysis of the membrane permeability of the seeds, the effects of different CAP treatment times on the germination were investigated. The results for treatment times ranging between $30 \mathrm{~s}$ and 5 min are depicted in Fig. 5. The total percentage of seed germination increased for CAP treatment times of up to 3 min compared to the control-possessing a highest percentage of germination for the 1 min CAP exposure $(89.2 \%)$. For a CAP treatment of $1 \mathrm{~min}$, the germination percentage, the speed of germination $(\mathrm{Vg})$, the shoot and root length, the seedling dry weight, and the vigor index (I and II) increased (Table 2), whereas the MGT of the seeds was decreased. Such an enhanced performance of germination characteristics of the seeds has not been reported earlier with a 1 min CAP treatment time.

However, Dubinov et al. (2000) exposed oat and barley seeds to continuous and pulsed glow discharge plasmas in air and concluded that the stimulatory effect on the germination and sprout growth was strongly dependent on whether the discharge was continuous or pulsed. Using low pressure microwave plasma discharges, Será et al. (2008), also observed a stimulatory effect on the seeds germination of Lamb's Quarters (Chenopodium album agg.). Their result

Table 2 Germination characteristics of Cicer arietinum for different CAP exposure times. For seedling length, dry weight, and vigor index, the data were expressed for ten randomly selected seedlings from each replicates

\begin{tabular}{|c|c|c|c|c|c|c|c|}
\hline \multirow{2}{*}{$\begin{array}{l}\text { Parameter } \\
\text { Treatment time }(\mathrm{min})\end{array}$} & \multirow{2}{*}{$\begin{array}{l}\text { GEM } \\
(\%)\end{array}$} & \multirow{2}{*}{$\begin{array}{l}\text { MGT } \\
\text { (day) }\end{array}$} & \multirow{2}{*}{$\begin{array}{l}\mathrm{V}_{\mathrm{g}} \\
\text { (seed/day) }\end{array}$} & \multirow{2}{*}{$\begin{array}{l}\text { Seedling length } \\
(\mathrm{cm})\end{array}$} & \multirow[t]{2}{*}{ Seedling dry weight (mg) } & \multicolumn{2}{|c|}{ Vigor Index } \\
\hline & & & & & & I & II \\
\hline Control & 60.8 & 3.5 & $3.9 \pm 0.1$ & $8.8 \pm 0.3$ & $25 \pm 1$ & 537.7 & 1.5 \\
\hline 0.5 & 70.8 & 2.8 & $5.5 \pm 0.1$ & $9.5 \pm 0.5$ & $26 \pm 3$ & 670.0 & 1.8 \\
\hline 1 & 89.2 & 2.7 & $7.1 \pm 0.1$ & $22.3 \pm 0.5$ & $55 \pm 2$ & 1985.7 & 4.9 \\
\hline 2 & 80.0 & 2.7 & $5.9 \pm 0.2$ & $18.0 \pm 0.6$ & $31 \pm 3$ & 1441.5 & 2.5 \\
\hline 3 & 65.0 & 2.8 & $4.9 \pm 0.2$ & $8.2 \pm 0.3$ & $22 \pm 2$ & 530.4 & 1.4 \\
\hline 4 & 55.0 & 2.9 & $4.1 \pm 0.1$ & $6.5 \pm 0.2$ & $14 \pm 2$ & 358.7 & 0.8 \\
\hline 5 & 30.0 & 2.8 & $2.3 \pm 0.1$ & $6.5 \pm 0.3$ & $18 \pm 2$ & 194.6 & 0.5 \\
\hline
\end{tabular}


Fig. 6 Cotyledon surface topography of Cicer arietinum: a before CAP exposure, $\mathbf{b}$ after 2 min CAP exposure, $\mathbf{c}$ after 4 min CAP exposure, and $\mathbf{d}$ after 5 min CAP exposure

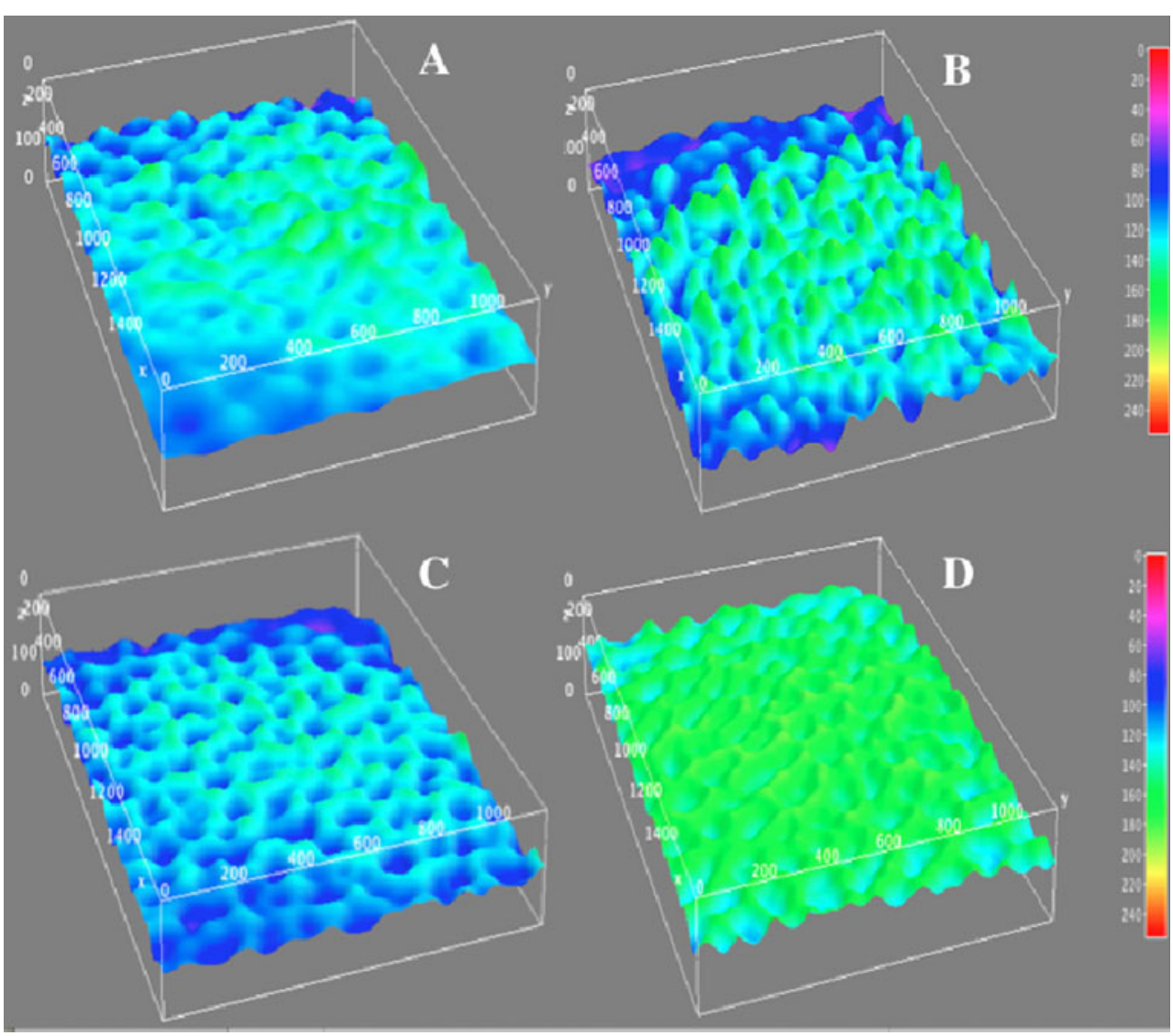

showed a three times increased (maximum $55 \%$ ) seed germination upon plasma treatment for 12 to $48 \mathrm{~min}$, compared to $15 \%$ germination of untreated seeds. Zhou et al. (2011) treated tomato seeds with a fabricated atmospheric pressure plasma device at 4.7 to $6.8 \mathrm{kV}$ for $6 \mathrm{~s}$ and observed stimulatory effects on blooming times, the height, the caulis, the extent of the plants, the average weight, and the length diameter of each fruit. However, the percentage of seed germination was not assessed.

In this experiment, the mechanism behind the observed increased germination is not completely understood, but it showed that the seed's physiological activity increases due to the CAP treatment for $1 \mathrm{~min}$. After $2 \mathrm{~min}$ of CAP treatment, the physiological effect decreased again. This could be due to overdose of reactive oxygen and nitrogen species produced by the CAP, as they have a significant role in the regulation of abscisic acid (ABA) catabolism and gibberellin (GA) biosynthesis during seed imbibition (Rajjou et al. 2012; Liu et al. 2010). ABA plays important role in the physiological processes such as seed dormancy, seed maturation, growth, and adaptive responses to environmental stresses, whereas GA is the major plant hormone in seed germination, stem elongation, leaf expansion, and seed development processes (Liu et al. 2010).

In another experiment, Libourel et al. (2006) showed that the external delivery of NO gas over the dormant seeds of
Arabidopsis thaliana stimulated the germination process. Kranner et al. (2010) pointed out the significant role of extracellularly produced reactive oxygen species during seed germination and early seedling development in Pisum sativum. Prior to germination, $\mathrm{OH}$ plays an important role for weakening of endospores in cress seeds (Müller et al. 2009).

\section{Surface Characteristics}

The inner surface topography of the cotyledon of $C$. arietinum was analyzed before and after the CAP treatment using ImageJ software (Fig. 6). The images show that the inner surface topography changes for different CAP

Table 3 Surface roughness statistics based on the topographical images of the inner surface of the cotyledon of Cicer arietinum after different CAP exposure times

\begin{tabular}{llll}
\hline & $\mathrm{R}_{\mathrm{a}}$ & $\mathrm{R}_{\mathrm{q}}$ & $\mathrm{R}_{\mathrm{ku}}$ \\
\hline Control & $105.6 \pm 0.9$ & $109.1 \pm 0.9$ & $1.23 \pm 0.01$ \\
$2 \mathrm{~min}$ & $103.3 \pm 0.4$ & $107.0 \pm 0.4$ & $1.28 \pm 0.02$ \\
$3 \mathrm{~min}$ & $106.0 \pm 0.5$ & $109.6 \pm 0.5$ & $1.24 \pm 0.01$ \\
$4 \mathrm{~min}$ & $109.1 \pm 1.5$ & $113.2 \pm 1.5$ & $1.28 \pm 0.01$ \\
$5 \mathrm{~min}$ & $139.4 \pm 1.6$ & $142.1 \pm 1.5$ & $1.14 \pm 0.01$ \\
\hline
\end{tabular}

$R_{a}$ arithmetic mean deviation, $R_{q}$ root mean square deviation, $R_{k u}$ kurtosis of the assessed profile 
exposure times. Significant changes of the roughness parameters were observed for CAP exposures of $5 \mathrm{~min}$ compared to the control (Fig. 6). To which extent the CAP influences the roughness profile of the seed cotyledon is summarized in Table 3. In 2006, Dhayal et al. modified safflower (Carthamus tinctorium L. semen) seed surfaces by treating them with a low pressure (16 Pa) radiofrequency ( $20 \mathrm{~W}, \mathrm{RF}$ power) argon gas discharge for $130 \mathrm{~min}$. In that case, the seed germination rate was increased by $50 \%$, and the germination time was reduced by the plasma treatment. However, scanning electron microscopy observations showed a significant physical structure modification of the seed coat and hilum of safflower seeds after plasma treatment.

\section{Conclusions}

A significant reduction of the seedborne microbial contamination was observed by CAP treatment. Furthermore, increased seed germination was achieved with treatment times of up to 3 min (compared to untreated control), with an optimum performance at $1 \mathrm{~min}$. The accelerated germination and the increased seed vigor beside the resulting reduction of the mean germination time signified an improved quality of the seeds. These results indicate that CAP technology could be the new and alternative processing technology in sprout production. However, the technology has to be optimized for commercial use.

Open Access This article is distributed under the terms of the Creative Commons Attribution License which permits any use, distribution, and reproduction in any medium, provided the original author(s) and the source are credited.

\section{References}

Abdul-Baki, A. A., \& Anderson, J. D. (1973). Vigor determination in soybean by multiple criteria. Crop Science, 10, 31-34.

Anonymous. (1999). Microbiological safety evaluations and recommendations on sprouted seeds. International Journal of Food Microbiology, 52, 123-153.

Basaran, P., Basaran-Akgul, N., \& Oksuz, L. (2008). Elimination of Aspergillus parasiticus from nut surface with low pressure cold plasma (LPCP) treatment. Food Microbiology, 25, 626-632.

Beuchat, L. R. (1996). Pathogenic microorganisms associated with fresh produce. Journal of Food Protection, 59, 204-216.

Bigelow, W. D., \& Esty, J. R. (1920). The thermal death point in relation to time of typical thermophilic organisms. Journal of Infectious Diseases, 27, 602-617.

Buchholz, U., Bernard, H., Werber, D., Böhmer, M. M., Remschmidt, C., Wilking, H., et al. (2011). German outbreak of Escherichia coli O104:H4 associated with sprouts. The New England Journal of Medicine, 365, 1763-1770.

Caetano-Anolles, G., Favelukes, G., \& Bauer, W. D. (1990). Optimization of surface sterilization for legume seed. Crop Science, 30, 708-712.
Chandrasekaran, S., Check, J., Sundararajan, S., \& Shrotriya, P. (2005). The effect of anisotropic wet etching on the surface roughness parameters and micro/nanoscale friction behavior of Si(100) surfaces. Sensors and Actuator, A, 121, 121-130.

Charkowski, A. O., Sarreal, C. Z., \& Mandrell, R. E. (2001). Wrinkled alfalfa seeds harbor more aerobic bacteria and are more difficult to sanitize than smooth seeds. Journal of Food Protection, 64, 1292-1298.

Chenoll, C., Betoret, N., \& Fito, P. (2009). Analysis of chickpea (var. "Blanco Lechoso") rehydration. Part I. Physicochemical and texture analysis. Journal of Food Engineering, 95, 352-358.

Chinga, G., Johnssen, P. O., Dougherty, R., Lunden-Berli, E., \& Walter, J. (2007). Quantification of the 3D microstructure of SC surfaces. Journal of Microscopy, 227, 254-265.

Costa, G. E., Queiroz-Monici, K., Reis, S., \& Oliveira, A. C. (2006). Chemical composition of dietary fiber and resistant starch contents of raw and cooked pea, common bean, chickpea, and lentil legumes. Food Chemistry, 94, 327-330.

Dhayal, M., Leea, S.-Y., \& Parkb, S.-U. (2006). Using low-pressure plasma for Carthamus tinctorium L. seed surface modification. Vacuum, 80, 499-506.

Dubinov, A. E., Lazarenko, E. R., \& Selemir, V. D. (2000). Effect of glow discharge air plasma on grain crops seed. IEEE Transactions on Plasma Science, 28, 180-183.

FAOSTAT (2004) Food and Agriculture Organization of the United Nations. http://faostat.fao.org/

Fett, W. F. (2006). Interventions to ensure the microbial safety of sprouts. In G. M. Sapers, J. R. Gorny, \& A. E. Yousef (Eds.), Microbiology of Fruits and Vegetables (pp. 187-209). Florida, USA: Taylor \& Francis.

Geeraerd, A. H., Valdramidis, V. P., \& Van Impe, J. F. (2005). GlnaFIT, a freeware tool to assess non-log-linear microbial survivor curves. International Journal of Food Microbiology, 102, 95-105.

Gilbert, R. J., Jde, L., Donovan, T., Little, C., Nye, K., Ribeiro, C. D., et al. (2000). Guidelines for the microbiological quality of some ready-to-eat foods sampled at the point of sale. Communicable Disease and Public Health, 3, 163-167.

Interactive 3D Surface Plot (2011) (Version V2.33). Internationale Medieninformatik, Berlin, Germany.

Izquier, A., \& Gómez-López, V. M. (2011). Modeling the pulsed light inactivation of microorganisms naturally occurring on vegetable substrates. Food Microbiology, 28, 1170-1174.

Klämpfl, T. G., Isbary, G., Shimizu, T., Li, Y.-F., Zimmermann, J. L., Stolz, W., et al. (2012). Cold atmospheric air plasma sterilization against spores and other microorganisms of clinical interest. Applied and Environmental Microbiology, 78, 5077-5082.

Kranner, I., Roach, T., Beckett, R. P., Whitaker, C., \& Minibayeva, F. V. (2010). Extracellular production of reactive oxygen species during seed germination and early seedling growth in Pisum sativum. Journal of Plant Physiology, 167, 805-811.

Laroussi, M. (2005). Low temperature plasma-based sterilization: overview and state-of-the-art. Plasma Processes and Polymers, 2, 391-400.

Libourel, I. G., Bethke, P. C., Michele, R. D., \& Jones, R. L. (2006). Nitric oxide gas stimulates germination of dormant Arabidopsis seeds: use of a flow-through apparatus for delivery of nitric oxide. Planta, 223, 813-820.

Li, Y.-F., Zimmermann, J. L., \& Morfill, G. E. (2012). Optimizing the distance for bacterial treatment using surface micro-discharge plasma. New Journal of Physics, 14, 023058.

Liu, Y., Ye, N., Liu, R., Chen, M., \& Zhang, J. (2010). $\mathrm{H}_{2} \mathrm{O}_{2}$ mediates the regulation of $\mathrm{ABA}$ catabolism and $\mathrm{GA}$ biosynthesis in Arabidopsis seed dormancy and germination. Journal of Experimental Botany, 61, 2979-2990.

Mafart, P., Couvert, O., Gaillard, S., \& Leguerinel, I. (2002). On calculating sterility in thermal preservation methods: application 
of the Weibull frequency distribution model. International Journal of Food Microbiology, 72, 107-113.

Maguire, J. D. (1962). Speed of germination-aid in selection and evaluation for seedling emergence and vigor. Crop Science, 2, 176-177.

Maity, J. P., Chakraborty, A., Saha, A., Santra, S. C., \& Chanda, S. (2004). Radiation induced effects on some common storage edible seeds in India infested with surface microflora. Radiation Physics and Chemistry, 71, 1065-1072.

Morfill, G. E., Shimizu, T., Steffes, B., \& Schmidt, H.-U. (2009). Nosocomial infections: a new approach towards preventive medicine using plasmas. New Journal of Physics, 11, 115019.

Müller, K., Linkies, A., Vreeburg, R. A., Fry, S. C., Krieger-Liszkay, A., \& Leubner-Metzger, G. (2009). In vivo cell wall loosening by hydroxyl radicals during cress seed germination and elongation growth. Plant Physiology, 150, 1855-1865.

Murthy, N. S. (2011). Techniques for analyzing biomaterial surface structure, morphology, and topography. In W. Rachel (Ed.), Surface modification of biomaterials -Methods, analysis and applications (pp. 232-254). Cambridge: Woodhead Publishing Limited.

Navarro, S., \& Donahaye, E. (2005). Innovative environmentally friendly technologies to maintain quality of durable agricultural produce. In S. Ben-Yehoshua (Ed.), Environmentally friendly technologies for agricultural produce quality (pp. 205-262). Boca Raton: CRC Press, Taylor \& Francis Group.
Rajjou, L., Duval, M., Gallardo, K., Catusse, J., Bally, J., Job, C., et al. (2012). Seed germination and vigor. Annual Review of Plant Biology, 63, 507-533.

Sadeghi, H., Khazaei, F., Yari, L., \& Sheidaei, S. (2011). Effect of seed osmopriming on seed germination behavior and vigor of soya bean (Glycine max L.). ARPN Journal of Agricultural and Biological Science, 6, 39-43.

Schnabel, U., Niquet, R., Krohmann, U., Winter, J., Oliver, S., Weltmann, K.-D., et al. (2012). Decontamination of microbiologically contaminated specimen by direct and indirect plasma treatment. Plasma Processes and Polymers, 9, 569-575.

Schneider, C. A., Rasband, W. S., \& Eliceiri, K. W. (2012). NIH Image to ImageJ: 25 years of image analysis. Nature Methods, 9, 671-675.

Selcuk, M., Oksuz, L., \& Basaran, P. (2008). Decontamination of grains and legumes infected with Aspergillus spp. and Penicillum spp. by cold plasma treatment. Bioresource Technology, 99, 5104-5109.

Será, B., Stranák, V., Serý, M., Tichý, M., \& Spatenka, P. (2008). Germination of Chenopodium album in response to microwave plasma treatment. Plasma Science and Technology, 10, 506-511.

Shine, M. B., Guruprasad, K. N., \& Anand, A. (2011). Enhancement of germination, growth, and photosynthesis in soybean by pretreatment of seeds with magnetic field. Bioelectromagnetics, 32, 474-484.

Zhou, Z., Huang, Y., Yang, S., \& Chen, W. (2011). Introduction of a new atmospheric pressure plasma device and application on tomato seeds. Agricultural Sciences, 2, 23-27. 